\title{
Original Design in a Copying - Intensive Industry
}

\author{
Maurício Moreira e \\ Silva Bernardes \\ Federal University of \\ Rio \\ Grande do Sul \\ (UFRGS) \\ Av. Paulo Gama, 110 - \\ Farroupilha, \\ Porto Alegre - RS, \\ 90040-060, Brazil
}

\author{
Graziela Brunhari \\ Kauling \\ Federal Institute of \\ Santa Catarina \\ Av. XV de Novembro, \\ $61-$ \\ Cidade Alta, Araranguá \\ - SC, \\ 88900-000, Brazil
}

\author{
Milena Chang \\ Chain \\ University of Quebec at \\ Trois-Rivières \\ 3351 Boulevard des \\ Forges, \\ Trois-Rivières, QC \\ G9A 5H7, Canada
}

\author{
Lars Löfqvist \\ University of Gävle \\ Kungsbäcksvägen, \\ 80267 Gävle, Sweden
}

\begin{abstract}
In some industries, copying is common and extensive. Most literature on the topic focuses on legal issues and interprets copying as a problem. To better understand the copying phenomenon, this study investigates the relationship between copying and design processes in five case companies in a copying-intensive industry. The findings reveal that unlike design processes, copying processes lack early conceptual activities. Furthermore, resources and contact with the end market are found to be prerequisites for professional and strategic design processes, whereas a lack of these better suits copying processes, especially in industries with low product variety and limited design problems.
\end{abstract}

\section{Keywords}

Copying, Design Management, Design Process

\section{INTRODUCTION}

Copying an existing product is a common activity in some companies and industries. In general, a company that copies is not preoccupied with differentiation and uses copying as a way to remain in the market and generate revenue. Copying is a part of American culture [1]; it is also widespread in various societies as a way of learning [2], and it "has long been a widespread practice throughout the world" [3].

It is not rare for a designer to develop a product similar to his or her competitor's [4]. According to Eckert and Stacey [5], "almost all design proceeds by transforming, combining and adapting elements of previous design, as well as elements and aspects of other objects, images and phenomena. Everything can be a source of inspiration to a designer." In this sense, there can be a fine line between an original product and a copy, and a firm's understanding of both concepts can place its products on either side of that line.

Most scientific studies that address copying have focused on the legal issues. These studies interpret copying as a problem that must be prevented [6-8] and not as a phenomenon that is intrinsically intertwined in the culture of particular market segments, such as the fashion-clothing industry. Despite the investment requirements of the fashion industry, there are few effective actions to prevent imitation. According to Barnett [9], "The fashion industry appears to sustain robust levels of investment in new product development even with widespread unauthorized imitation, few effective legal defenses against counterfeiters, and relatively meager state prosecution of counterfeiting operations". Since the beginning of the last century, it has been common to go to Paris to get new ideas to bring to America [10], a clear example of the copy culture in the fashion-clothing industry.

The copy culture also appears to be present in some small Brazilian fashion-clothing companies. In the south of Brazil, there is a group of small fashion-clothing companies for which copying could be considered their core competence. This constitutes a new opportunity for research. The mechanisms related to the copying process and the reasons that businesses choose to copy must be studied; this is the main theoretical contribution of this article. To better understand the copying phenomenon, it is important to study different companies that consider copying a common process in their industry and market along with companies that conduct design processes to more clearly observe the differences and similarities between products. Based on this context, we aim to understand how fashion-clothing companies address copying when designing new collections.

\section{DESIGN PROCESSES}

Many different design process models exist [11]. These are often claimed to be general and non-domain specific [12,13], and they describe the design process with different amounts of detail [11]. These models share a set of basic activities: investigating the design problem, generating solutions for it, evaluating the solutions, and communicating the solution through the product development process. In the design process, the design problem is solved and manifested in the new product [14]. Design problems are among the most illstructured and complex types of problems experienced in practice; they include many unknown elements, are vaguely defined, and allow multiple solutions [15]. Most design process models aim to create original and novel design from scratch [12], which means that they are less suitable for partly original designs, such as redesigned products and small improvements to existing products.

Design processes are affected by their context, such as the company responsible for the design, the market and the product under development [12,13]. Small and large companies conduct design in different ways. This is generally not considered by prevailing design theory, which has focused on and mostly been derived from research on larger companies [16]. Small companies find design to be costly and time consuming [17], and the literature lacks design process models that are adapted to suit small companies [16]. Exceptions to this are a study by Bruce et al. [18] that presents a linear model of the design process suitable for small companies; one by Ammar, Scaravetti, and Nadeau [19] that proposes a highly structured, mechanistic design process 
model for small and middle-sized manufacturing companies; and a paper by al-Tarawneh et al. [20] that presents a design process model for small software development companies. The design process model by Bruce et al. [18] advocates organizing design work as a formal project with a project team.

\section{COPYING}

The sale of counterfeited products has been increasing worldwide at a disconcerting rate [21]. In this scenario, given the many choices available, many companies choose a strategy of copying others [2,22]. The copying process itself can be understood as a way to enhance company performance [23].

In the fashion industry, the concept of copying is recognized as an accepted practice in the market [24]. According to Csaszar and Siggelkow [23], "firms are exhorted to invest in capabilities that allow them to more quickly and extensively copy others, to implement 'best practices,' and to invest in absorptive capacity." The copying culture is supported by the idea that innovation in fashion is driven by the easy transfer of designs [3].

A copy can manifest in two ways according to the consumer's point of view: deceptive or nondeceptive [21]. In the deceptive form, the buyer does not recognize the product as counterfeit. In the second case, the consumer recognizes that the product is fake, and his or her moral judgment can influence the purchase decision [25]. When there is a deliberate intention to buy a copy, the consumer recognizes the nondeceptive counterfeit [21]. In these cases, the purchase has a high chance of being completed when the features of the copy are very close to those of the original [26]. Another aspect that influences the decision to buy a copy is its price [27]. If the price of the original is sufficiently low, the customers may decide to buy the original instead of the copy [28].

Pesendorfer noticed that companies that copy original designs operate in turbulent markets with a large number of new products released every day [29]. He wrote, "Fashion is accompanied by a process of continuous innovation, in which new designs are developed at sometimes large cost only to be replaced by other designs. With the arrival of every new design, previous fashions become obsolete" (p. 772). To produce a law that inhibits the copy process, it is necessary to consider the speed with which new clothing collections are launched. In general, laws have been better at protecting the logos and brand names of fashion houses than the fashion design itself $[3,30]$. Research on copying as a process appears to be limited in the academic literature; most research on copying has focused on other areas, such as legal issues and economic effects.

There are three basic ways to use ideas from pre-existing products in the market to support the development of a new product. Figure 1a shows that a product can be copied entirely from an original one. This is the case with counterfeited products $[8,9]$, which have generated discussion about the legal and ethical issues related to copying [7,28,31]. (a)
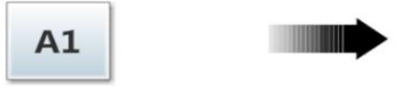

A2

(b)
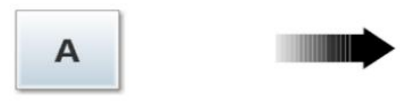

AB

(c)
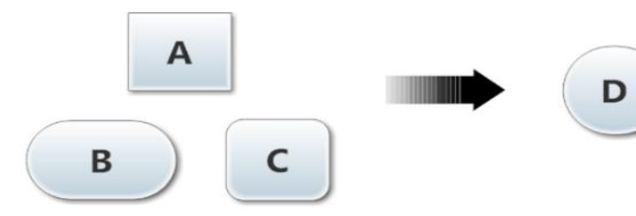

Fig 1: The different situations in which pre-existing ideas
are used as input for the development of a new product or
the production of a copy

In another case, the product that is being launched is considered to be an improvement of an existing product or it only has some features of the original (Figure 1b). This can be interpreted as an improvement of previous ideas as part of a continuous improvement process. In the third type of case, such as the "fast-fashion" segment (i.e., the area of the fashion industry in which companies aim to bring the latest consumer trends to the market as quickly as possible), original ideas are interpreted as market tendencies. Thus, there is a slight modification in the product that is launched, but its features resemble the original. This practice appears to be common in the fashion industry [4], [29]. An example of a modification may be the cut or shape of the garment.

The last case of using ideas found in existing products to develop a new product is shown in Figure 1c. In this case, the ideas come from different sources [22], and the result is a product with some features that resemble the original but that is still considered a new product. Figure 1c captures the conceptual work and creative dimension inherent in this type of design [14] because it presents more opportunities to rearrange different ideas in new ways. This corresponds to the classic definition of creativity as the "novel combinations of old ideas" [32]. Figure 1a shows a lower need for creativity such as copying processes because there are fewer possible combinations of ideas. Figure $1 \mathrm{~b}$ can be seen as falling between the two extremes.

\section{RESEARCH METHOD}

This study's exploratory and explanatory research questions aim to study copying and design processes in context. Qualitative case study research is an appropriate research design for exploratory and explanatory studies when the phenomenon under study is complex and difficult to isolate from its real-life context [33]. Thus, qualitative case study research was chosen for this study.

Further, it is important to choose cases that are highly likely to help answer the research questions [33]. The literature has identified the fashion industry as copying intensive $[9,10]$. In addition, the Brazilian clothing industry is immature in terms of design [34-37], which increases the probability of finding companies in this industry that copy rather than focusing on original design. Companies that copy are further found to operate in turbulent markets that have a high number of new products released daily [29]. Because small companies most often work in turbulent markets [38-40] and because the fashion industry launches a high number of new products 
[41], small Brazilian clothing companies are particularly suitable for studying copying processes.
Five small Brazilian fashion-clothing companies were chosen for inclusion in the study, identified as Company A, B, C, D

Table 1. Number of employees, market value and turnover of the studied companies

\begin{tabular}{llllll}
\hline Variables & Company $A$ & Company $B$ & Company $C$ & Company D & Company E
\end{tabular}

\section{Number of}

Employees

Market Value

400000

16

21

29

55

39

(US\$)

Annual Turnover

(US\$)
970000
4320000

The company did

not answer and $\mathrm{E}$ to prevent identification. These companies are located in the city of Araranguá, Santa Catarina, in the south of Brazil. To compare copying and design processes, both types of processes must be studied to better identify the differences and similarities. Initially, it was uncertain which companies conducted copying versus design processes, but both types of processes were found, facilitating direct comparison.

Data were collected through two-hour interviews with the general managers of the companies. The interviews were conducted in Portuguese in an unstructured to semi-structured format [42] and covered themes and predefined questions about the companies' design activities and product development processes. Curran and Blackburn [43] found unstructured and semi-structured interviews to be an efficient and effective way to collect data from owner-managers in small companies. In the interviews, the product development processes were tracked in sequence, and questions were asked regarding design. The design process model by Bruce et al. [18] was used as a reference model for mapping the product development processes. This model was chosen because it is linear and comprehensive, with distinct stages and activities that facilitate a focus on both the entire product development process and on each distinct stage and activity. Furthermore, the authors showed the model's validity for different types of small companies in different industries. The themes covered in the interviews focused on the company, its design activities and its markets. The questions covered each company's age, history, number of employees, vision and strategy, market, economic figures and products. Regarding design, the questions covered the meaning of, attitudes toward and value of design for the companies, the strategic dimensions of design, the level of professionalism in design, the organization of design activities, the persons involved, sourcing, and the processes for providing briefings on and evaluating ideas or concepts for new products. Some questions were not answered by all companies. Questions about market value and turnover may have been considered too private, and these were not answered by two companies.

Data analysis was performed by mapping the different companies' product development processes in sequence with the help of the model of Bruce et al. [18]. Stages and activities covered as well as the level of execution for activities were identified. Answers were transcribed, separated by affinity and listed in summary charts according to the different categories found in the data. Finally, a cross-case analysis [42] was performed to better observe the similarities and differences in the findings from the five companies.

\section{FINDINGS}

The number of employees, market value and turnover for the fast-fashion companies studied are presented in Table 1.

Regarding design, the companies expressed different contexts and understandings. Table 2 shows how each company positioned itself in terms of design. None of the companies identified design as a strategic tool or a competitive factor; they focused more on the physical appearance of their products. The lack of a strategic concept of design is further shown by their understanding of design management. The companies gave quite divergent answers to these questions or were unable to answer at all. This lack of strategic awareness was further demonstrated by the fact that only two of the companies had an overall company strategy.

Table 2. Profile of the studied companies in relation to design

\begin{tabular}{llllll}
\hline Variable Company $A$ & Company $B$ & Company C & Company D
\end{tabular}

Interpretation of the

meaning of design

\section{Innovation, novelty, Something new}

Style and creation visual aspects and

aesthetics to be applied in

the company
Format and mold

Composition of

ready pieces 
Document and

$\begin{array}{lllll}\text { Understanding of } & \text { record the } & \text { Planning, control } & \text { Unable to } & \text { Unable to answer } \\ \text { design management } & \text { management of the } & \text { and management } & \text { answer } & \end{array}$
design process

Company-wide

strategic planning

Source of design ideas Types A and B

Customized trims

Added value in

products

and sewing

materials

Defined target

market?

Market channel for

sales

Wholesale

Wholesale
Wholesale

Retail

Investment

Investment

Structure of

clothing and

quality

Modeling and

quality

Partly

Cost

investment?

Cost

No

No

Investment

No

Use of collection

themes

No

Yes

No

In the study, products were classified into three new product development categories, types A, B and C, corresponding to Figures 1 a-c. Four of the five companies showed that the sources of ideas manifested in new products were within the copying-related categories $\mathrm{A}$ and $\mathrm{B}$, containing minor or no modification in comparison with an original design. Only Company D created category $\mathrm{C}$ products, which indicates that their new products required a higher amount of original design. Regarding added value, the answers show a rather low degree of modification and improvement of new products.

With regard to the target market, none of the companies presented a clear definition of the public they served. Three companies did not have a defined target market for their products, and two companies had a target that was only partially defined. It is worth noting that a more comprehensive focus on the consumer profile increases the difficulty of establishing a brand name concept and unique products. Conceptual brand names generally establish a specific customer focus by researching behavior, anticipating consumer requirements, increasing demand for a unique product design and, above all, acquiring customers who are trendsetters in anticipation of mass media campaigns. Table 2 also shows that four of the companies sold their products to wholesalers that in turn sold to retailers; only Company D sold directly to retailers.

At the fashion shows of regional brands, one can observe similarities between the fashion clothes from different companies. These similarities stem from shared research sources, such as the public websites of international and national brands, subscription websites, trade fairs, international trips to study store showcases of famous brands, lectures on micro trends conducted by fabric suppliers, international magazines and soap operas on Globo (the Brazilian television network). All companies studied used these sources as the inspiration and foundation of their product development. Thus, these companies worked with trends at a mass media level, a stage at which various people adapt trends that can already be seen on the streets $[35,44,45]$. The process of collecting data using these research sources is called fashion forecasting [45]. Despite the existence of commercial fashion forecasting agents in the market, the studied companies considered their style books and 
specifications too expensive and did not use them. Instead, they collected market and trend information themselves from the above-mentioned mass media sources.

Figure 2 shows the product development processes at the examined companies mapped onto the design management process model by Bruce et al. [18]. Realized, partly realized and unrealized activities in the processes are shown for each product development process.

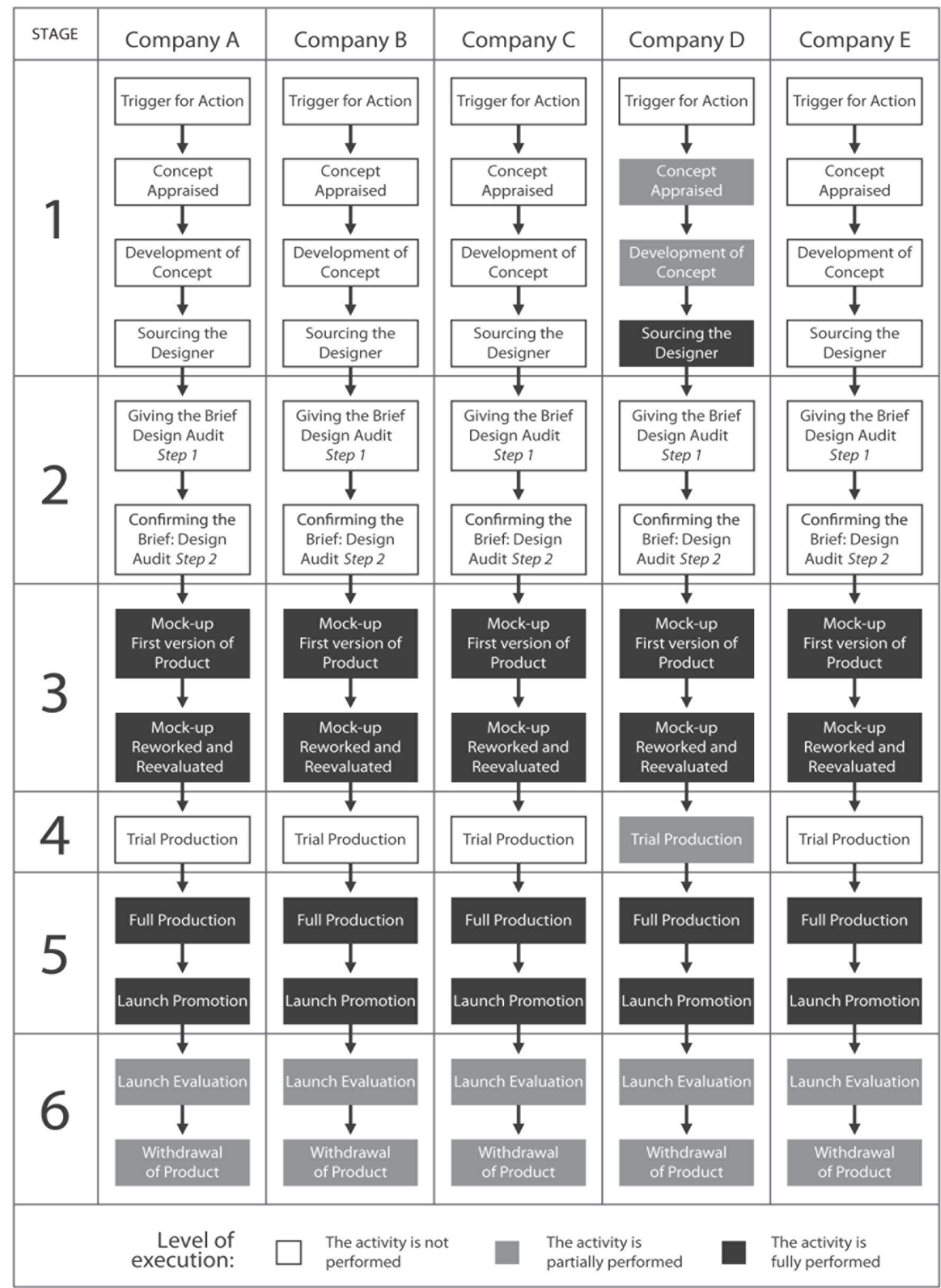

Fig 2: The product development processes in the studied companies mapped onto the design process model. Adapted from Bruce et al. [18] 
Stage 1 in Figure 2 represents the preparation of the concept and is connected with the strategic area. Only Company D prepared the concept, specified the product development project and fully carried out the sourcing of the necessary designers because it had a team of three professional in-house designers. Stage 2 shows that none of the studied companies fully conducted briefing activities to specify the design activities and design task. Stage 3 demonstrates that all of the companies performed mock-up activities, creating prototypes and revising the product prior to manufacturing. Stage 4 shows that only Company D worked with trial production. Because it is the only company with a focus on retail distribution, it needed to obtain detailed feedback on new products from retailers. Regarding stage 5, all companies conducted full production and promoted the launch of their products. For stage 6, all companies conducted partial evaluations of the products in terms of sales performance, but these cannot be considered strategic evaluations as proposed by Bruce et al. [18] because they are more focused on economic feedback such as the amount of sales.

Figure 2 shows that several stages, including sourcing, briefing and evaluation, differ between the companies or are only partially realized. These stages and differences are further clarified in Table 3 below.

Of the five studied companies, none conducted briefing activities: two companies did not know the meaning of this term, and the other three described briefing using a sense different from that of Bruce et al. [18]. The probable explanation for this result is that the studied companies did not develop projects based on specific needs or circumstances because the collection projects followed a fixed time span of six months and were usually similar.

Table 3. The sourcing, briefing, and evaluation activities in the studied companies

\begin{tabular}{|c|c|c|c|c|c|}
\hline Bariables & Company A & Company B & Company $C$ & Company D & Company E \\
\hline Understanding of briefing & $\begin{array}{l}\text { They do not } \\
\text { know }\end{array}$ & They do not know & $\begin{array}{l}\text { Visual panel and } \\
\text { collection text }\end{array}$ & Collection text & Internal design \\
\hline Briefing process & No & No & No & No & No \\
\hline \multicolumn{6}{|l|}{$\begin{array}{l}\text { Sourcing } \\
\text { activities }\end{array}$} \\
\hline Internal or external design & Internal & Internal & Internal & Internal & Internal \\
\hline $\begin{array}{l}\text { Experience with external } \\
\text { design }\end{array}$ & $\begin{array}{l}\text { Yes. In the past } \\
\text { with designer } \\
\text { from a fashion } \\
\text { school }\end{array}$ & Never & Never & $\begin{array}{l}\text { Yes. In the past } \\
\text { with designer } \\
\text { from a fashion } \\
\text { school }\end{array}$ & $\begin{array}{l}\text { Yes. In the past } \\
\text { with designer from } \\
\text { a fashion school }\end{array}$ \\
\hline $\begin{array}{l}\text { Responsibility for product } \\
\text { development }\end{array}$ & Family member & $\begin{array}{l}\text { The owner- } \\
\text { manager }\end{array}$ & $\begin{array}{l}\text { The owner- } \\
\text { manager }\end{array}$ & $\begin{array}{l}\text { Professional } \\
\text { designers }\end{array}$ & $\begin{array}{l}\text { The owner- } \\
\text { manager }\end{array}$ \\
\hline Creation department & No & No & No & Yes & No \\
\hline \multicolumn{6}{|l|}{$\begin{array}{l}\text { Evaluating } \\
\text { activities }\end{array}$} \\
\hline Evaluation interval & $\begin{array}{l}\text { Every fifteen } \\
\text { days }\end{array}$ & Weekly & Every fifteen days & $\begin{array}{l}\text { Depending on } \\
\text { orders }\end{array}$ & Weekly \\
\hline Criteria used & $\begin{array}{l}\text { Sales } \\
\text { performance }\end{array}$ & Sales performance & Sales performance & $\begin{array}{l}\text { Evaluation of } \\
\text { previous } \\
\text { collections and } \\
\text { sales } \\
\text { performance }\end{array}$ & Sales performance \\
\hline
\end{tabular}

All companies performed design in house. At four of the companies, the businessperson or a family member functioned as the designer. Only Company D had professional designers, a creation team and a creation department, with tasks oriented toward product development. Although some of the people performing the design function had a technical or higher degree in the fashion area, frequently, the acquired knowledge was not put into practice. This finding shows that even with acquired competencies in design, the companies did not or could not apply their competence. This was noted in an interview with one of the studied companies whose ownermanager had a technical degree in fashion. Thus, it is not sufficient to have a degree in the area; rather, someone must act as a transformation agent for company practices to apply the acquired knowledge. The companies all had minimal experience in the use of external design. Two companies had never hired project freelancers, whereas three companies had, but they did not consider the hiring of freelancers a potential strategy. The sourcing method most frequently mentioned was hiring a designer from a fashion school by word of mouth. One of the companies did not know the answer to this question.

Concerning the evaluation activities, the criteria for analysis included evaluating market success through sales 
performance, evaluating briefing and corporate design, and evaluating performance by comparison with the competition. Therefore, one of the questions in the interviews involved the degree of knowledge about competitors. The life cycle of fashion products is extremely short, so the stores must be supplied on an almost daily basis, and the company must conduct a follow-up evaluation of products that have been recently introduced into the market. Two companies performed a weekly analysis according to the criterion of sales performance. One of the owner-managers prepared a weekly sales report, and the decision to continue a product was made according to its sales performance. In contrast, Company $\mathrm{D}$ based its evaluation on retailer orders. In the sales schedule, the product had a defined market time; thus, every eight weeks, a new mini-collection was introduced to retailers. There was no daily product supply. However, the evaluation was restricted to sales performance and was not a general evaluation of the entire season. There were no reports on what worked well, failures and successes, competitive analysis, or concept evaluation. Thus, the companies conducted only partial evaluation activities.

\section{ANALYSIS AND DISCUSSION}

The findings show that Company D differs considerably in comparison with the other companies. This company works with collection themes, rethinks the brand concept (even if informally), and creates (verbal) strategies to position the brand. Company D also conducts the highest number of activities proposed by Bruce et al.'s [18] model, engages more professionals in those functions and organizes product development with a more project-like structure. The company also has future plans, including a company vision and overall strategy, and as an organization, it has specialized departments such as creation marketing. One explanation for these differences could be that this company is larger, has more resources, is closer to the end market, focuses on retail, and obtains more intense, clear and objective communication with end users via the point of sale.

In general, the development of new products requires the participation of several functions, such as marketing, research and development, design, production and sales. Company D participates in these functions more effectively within the process as a whole. Company $\mathrm{D}$ reaches retailing markets directly, which enables more direct competition than the other studied companies, and it is better informed about end users' needs and requirements. The company plans its collections far earlier than the other studied companies and has a more formalized management process in place. Formalization occurs when employees and managers are guided by someone else, when the departments are instructed about what has to be done. The owner of Company D is involved in most of the processes as a coordinator, rather than as a task executor. In Company $\mathrm{D}$, it is possible to identify a more intense formalization process, as well as a more structured methodology, in comparison to the other companies. The target market of Company D is partially defined, allowing a clearer identity for the brand and its products, a situation that may be related to the strategic aspects of Bruce et al.'s [18] model.

Company D is the only company in this study that performs conceptual activities, such as sourcing, trial production and promotion. However, it performs other activities differently or incompletely compared to the model by Bruce et al. [18]. Some fundamental elements of the model, such as briefing, are not included, whereas Company D completely performs sourcing because it has a professional, specialized creation team. Evaluating is performed, but it does not include the evaluation of strategies. The above characteristics differentiate Company D from the others and yield results that are more similar to the reference model. Company D follows most of the steps suggested in the reference model, thereby developing products of type $\mathrm{C}$ (Figure 1c), which require a higher amount of creativity in the design processes [14]. By performing these conceptual activities, Company $\mathrm{D}$ is able to produce more original designs and to aim for a more defined target market. The companies that do not engage in activities such as concept development, sourcing and evaluating demonstrate a lack of strategic action, thus hindering their ability to offer products of original design. These results were also found by Bruce et al. [18] when they tested their model. Thus, companies that incorporate the largest number of model stages and activities obtain better results in terms of producing original design. It can be concluded that Company D conducts design processes by creating type $\mathrm{C}$ products (Figure 1c) and performing most of the activities and tasks included in the reference model. It can also be concluded that Company D conducts professional and strategic design by including professional designers and strategic dimensions in its design processes.

Companies A, B, C and E are smaller and have fewer economic resources. A resource perspective can explain why these companies copy and performed copy processes. Design processes demand resources, and small companies generally have scarce resources $[40,46,47]$. Small companies also often consider design to be costly and time consuming [17]. The size of a company is an indicator of the available resources [48]. Only Company D, the largest company in the study, was found to conduct design processes. In the early conceptual activities of the design process, the design problem is examined and defined. Company D had an ill-defined design problem to solve because it had no concept to copy from another product; it had to put resources into concept development and to use professional designers to determine the final product's requirements and appearance. The other companies did not perform original design but copied existing products, which means that the design problems they needed to solve were limited and defined because they knew with high certainty what the final products would be (i.e., something very similar to the products they were copying). This limits or excludes those early conceptual activities that require professional design skills. Skipping the early conceptual activities and eliminating the professional designer and market research saves resources, allowing these companies to manufacture and sell products without investing in conceptual activities. Copying permits products to be launched and to generate revenue through operational processes such as production, promotion and sales, omitting the more strategic and resource-consuming conceptual activities that exist in design processes.

In conclusion, despite the legal and moral issues surrounding copying, it appears to suit companies that suffer from scarce resources. Copying seems to work well because these companies generate revenue and survive by conducting business this way.

An additional finding is that for design management, the lack of strategy in small companies is problematic. Companies $\mathrm{C}$ and $\mathrm{D}$, but not $\mathrm{A}, \mathrm{B}$ and $\mathrm{E}$, had company-wide strategic plans, but none of the companies considered design a strategic tool or a competitive factor. Strategy means making plans for the future [49], but small companies have difficulties predicting the future due to their turbulent environment $[38,39]$. This 
makes the future state of the company, market and resources uncertain. Contributing to this uncertainty is a preference for quick returns on investments [50,51], which is connected to the need for a consistent cash flow [38,51,52]. Small companies with scarce resources cannot wait long for a return on their investments in professional and strategic design. Company D appeared to informally incorporate more strategy in its design activities when working on collection themes, but this company had more resources to invest in strategic work. Larger companies have been shown to be more bureaucratic and to rely on formal approaches to enable communication and coordination [46,53]. Because the departments at Company D were more separate, formal approaches, such as structured project work, were necessary for communication and coordination. These approaches are less flexible, which means that the company must have a strategy and a clear direction. Furthermore, Company D directly targeted the retail business, which requires more detailed marketing and trend information to support strategic and professional design. The copying companies adapted trends on a mass media level and sold their products to wholesalers, not end users, making target market identification more difficult.

It is probable that some product categories are easier to copy than others are. The copying companies copied fashion clothes in their product development processes, which presumably demands less work and fewer resources. In general, fashion clothing is not high tech or overly complex, which yields a limited design problem to solve and, in turn, facilitates easy copying.

A design process is affected by its context and the product to be developed $[12,13]$. The above discussion provides some answers regarding how design processes are affected by product, company and market characteristics. Fashion clothing must be considered to be relatively easy to copy because it is characterized by less variation in design and appearance, relatively low complexity and limited design problems. In addition, many products are similar, which makes it less relevant whether a new product is copied. Thus, product categories with less variation, low complexity and limited design problems facilitate copying processes over design processes.

One interesting finding from the above discussion is that the primary explanation for whether professional and strategic design can be conducted lies in resource availability and good access to knowledge from the end market and end users. In this latter context, there is room for professional designers and strategic design. Some of the owner-managers involved in the product development processes at the copying companies held professional degrees in fashion, but they could not practice their knowledge and skills, which resulted in copying. The inability to use their skills likely stems from a lack of resources and a lack of contact with end users' needs and requirements.

\section{CONCLUSIONS}

A copying process does not cover all of the stages and activities of a design process. In particular, the early conceptual activities in design processes are lacking in copying processes. These early conceptual activities do not appear to be needed in copying processes because the product concept is largely defined at the outset by the product to be copied.

Design processes are affected by company, product and market characteristics. Factors such as scarce resources, a lack of communication and integration with the end market and limited knowledge of end users' needs and requirements make design processes difficult and copying processes more appropriate for some companies.

Resources and good contact with the end market and end users are fundamental for design processes. Professional designers and a strategy are secondary prerequisites for professional and strategic design. In addition, copying processes are more suitable if the product category has less design and appearance variation and limited complexity and design problems. Together, these findings mean that design processes are affected by such contextual factors as the product, the company and the market, which results in a reasonable explanation for the copying phenomenon.

This research has shown some of the mechanisms behind copying and copying processes and revealed some of the differences and similarities between copying and design. This understanding may support a more nuanced discussion of the two concepts. Further, this work shows that professional and strategic design not only requires professional designers and an overall strategy but also needs available resources and contact with the end market and end users. Therefore, it may not be suitable for companies with limited resources and limited contact with the end market to implement professional and strategic design. This advice could help organizations that support design to select which companies to support. Introducing design in a company with scarce resources and lack of contact with the end market and end users may be a wasted effort because the basic prerequisites for design processes are lacking.

This study takes a neutral view of the copying process and its relation to design processes; however, it does not cover the moral and legal issues involved with copying. These aspects of copying processes could be interesting for further research. Possible future research questions might be as follows. Is there a trade-off between the legal risks of copying and the cost of creating original design? How does this trade-off affect the decision to copy? Is it safer and more cost efficient to copy despite the legal risk? In particular, for those companies that suffer from scarce resources to invest in design, these questions may be relevant and interesting to explore.

\section{REFERENCES}

[1] Schwartz, H. 1996. The Culture of the Copy: Striking Likenesses, Unreasonable Facsimiles. Zone Books.

[2] Ormerod, P. and Bentley, R. A. 2010. Modelling creative innovation. J. Cult. Sci. 3 (1), 1-15.

[3] Eguchi, A. 2011. Curtailing copycat couture: the merits of the innovative design protection and piracy prevention act and a licensing scheme for the fashion industry. Cornell Law Rev. 97 (1), 131-158.

[4] Person, O., Schoormans, J., Snelders, D., and Karjalainen, T. M. 2008. Should new products look similar or different? The influence of the market environment on strategic product styling. Des. Stud. 29 (1), 30-48.

[5] Eckert, C. and Stacey, M. 2000. Sources of inspiration: a language of design. Des. Stud. 21 (5), 523-538.

[6] Woods, A., Coles, A. M., and Dickson, K. 1999. Copyright awareness and training for textile design protection. J. Eur. Ind. Training 23 (7), 329-334. 
[7] Scruggs, B. 2007. Should fashion design be copyrightable? Northwest. J. Technol. Intellect. Prop. 6 (1), 122-137.

[8] Staake, T., Thiesse, F., and Fleisch, E. 2009. The emergence of counterfeit trade: a literature review. Eur. J. Mark. 43 (3/4), 320-349.

[9] Barnett, J. M. 2005. Shopping for Gucci on Canal Street: reflections on status consumption, intellectual property, and the incentive thesis. VA. Law Rev. 91 (6), 13811423.

[10] Moreira, E. and Shaw, E. 1992. High fashion: the search for a style. J. Décor. Propaganda Arts 18, 171-187.

[11] Howard, T. J., Culley, S. J., and Dekoninck, E. 2008. Describing the creative design process by the integration of engineering design and cognitive psychology literature. Des. Stud. 29 (2), 160-180.

[12] Clarkson, J. and Eckert, C. 2005. Design Process Improvement: A Review of Current Practice. Springer.

[13] Karlson, B. 1994. Product Design: Towards a New Conceptualization of the Design Process (Unpublished PhD Dissertation). The Royal Institute of Technology.

[14] Cross, N. 2008. Engineering Design Methods: Strategies for Product Design. Wiley.

[15] Jonassen, D. H. 2000. Toward a design theory of problem solving. Educ Technol. Res. Dev. 48 (4), 63-85.

[16] Moultrie, J., Clarkson, P. J., and Probert, D. 2007. Development of a design audit tool for SMEs. J. Prod. Innov. Manage. 24 (4), 335-368.

[17] Berends, H., Reymen, I., Stultiëns, R. G. L., and Peutz, M. 2011. External designers in product design processes of small manufacturing firms. Des. Stud. 32 (1), 86-108.

[18] Bruce, M., Cooper, R., and Vazquez, D. 1999. Effective design management for small businesses. Des. Stud. 20 (3), 297-315

[19] Ammar, A. A., Scaravetti, J. P., and Nadeau, J. P. 2011. Adaptation and implementation of a process of innovation and design within a SME. Proceedings of the IMProVe 2011 - International Conference of Innovative Methods in Product Design 2011.

[20] al-Tarawneh, M. Y., Abdullah, M. S., and Ali, A. B. M. 2011. A proposed methodology for establishing software process development improvement for small software development firms. Procedia Comput. Sci. 3, 893-897.

[21] Penz, E. and Stöttinger, B. 2005. Forget the "real" thing - take the copy! An explanatory model for the volitional purchase of counterfeit products. Adv. Consum. Res. 32 (1), 568-575.

[22] McAdam, R. and McClelland, J. 2002. Sources of new product ideas and creativity practices in the UK textile industry. Technovation 22 (2), 113-121.

[23] Csaszar, F. A. and Siggelkow, N. 2010. How much to copy? Determinants of effective imitation breadth. Organ. Sci. 21 (3), 661-676.

[24] Marcketti, S. B. and Parsons, J. L. 2006. Design piracy and self-regulation: the fashion originators' Guild of America, 1932-1941. Clothing Textiles Res. J. 24 (3), 214-228.
[25] Kim, J. E., Hyeon Jeong, C., and Johnson, K. K. P. 2009. Influence of moral affect, judgment, and intensity on decision making concerning counterfeit, gray-market, and imitation products. Clothing Textiles Res. J. 27 (3), 211-226.

[26] Lai, K. K. Y. and Zaichkowsky, J. L. 1999. Brand imitation: do the Chinese have different views? Asia Pacific J. Manag. 16 (2), 179-192.

[27] Cordell, V. V., Wongtada, N., and Kieschnick, R. L. 1996. Counterfeit purchase intentions: role of lawfulness attitudes and product traits as determinants. J. Bus. Res. 35 (1), 41-53.

[28] Takeyama, L. N. 1997. The intertemporal consequences of unauthorized reproduction of intellectual property. J. Law Econ. 40 (2), 511-522.

[29] Pesendorfer, W. 1995. Design innovation and fashion cycles. Am. Econ. Rev. 85 (4), 771-792.

[30] Gottlieb, G., Misthal, M., and Kolsun, B. 2010. An introduction to intellectual property protection in fashion. In Fashion Law: A Guide for Designers, Fashion Executives, and Attorneys. Fairchild Books.

[31] Handler, S. P. 1971. Copyright protection for massproduced, commercial products: a review of the developments following Mazer v. Stein. Univ. Chic. Law Rev. 38 (4), 807, 818-820.

[32] Boden, M. A. 1994. What is creativity? In Creativity in Human Evolution and Prehistory, Mithen SJ, Routledge.

[33] Yin, R. K. 2009. Case Study Research: Design and Methods. SAGE Publications.

[34] Bonsiepe, G. 1997. Design: Do Material ao Digital [Design: from Material to Digital]. FIESC/IEL.

[35] Keller, J. 2004. A Gestão do Design na Moda: Processos que Agregam Valor e Diferencial ao Produto de Moda [Design Management in the Fashion Industry: Processes that add Value and Differentiate the Fashion Product] (unpublished master's thesis). Florianópolis, Brazil.

[36] Naveiro, R. M. 2008. Design education in Brazil. Des. Stud. 29 (3), 304-312.

[37] Minuzzi, R. de. F. B., Pereira, A. T. C., and Merino, E. A. D. 2008. Teoria e prática na gestão do design [Theory and practice in design management]. In Proceedings of the 4o Congresso Internacional de Pesquisa em Design.

[38] Welsh, J. A., White, J. F., and Dowell, P. 1981. A small business is not a little big business. Harv. Bus. Rev. 59 (4), 18-32.

[39] Ratcliffe-Martin, V. and Sackett, P. 2001. Information and small companies: Chaos with intent. AI Society 15 (1), 22-39.

[40] Zontanos, G. and Anderson, A. R. 2004. Relationships, marketing and small business: an exploration of links in theory and practice. Qual. Mark. Res. Int. J. 7 (3), 228 236.

[41] Ribeiro, G. 2009. Vantagens competitivas das empresas de moda: cenário nacional e internacional. In Proceedings of $3^{\circ}$ Simpósio Nacional de Moda e Tecnologia. 
[42] Voss, C., Tsikriktsis, N., and Frohlich, M. 2002. Case research in operations management. Int. J. Operations Production Manag. 22 (2), 195-219.

[43] Curran, J. and Blackburn, R. A. 1994. Small Firms and Local Economic Networks: The Death of the Local Economy? Paul Chapman Publishing.

[44] Treptow, D. 2003. Inventando Moda: Planejamento de Colecao. D. Treptow.

[45] Jones, S. J. 2005. Fashion Design: Manual do Estilista [Stylist manual]. Cosac Naify.

[46] Ghobadian, A. and Gallear, D. 1997. TQM and organization size. Int. J. Operations Production Manag. 17 (2), 121-163.

[47] Rothwell, R. and Dodgson, M. 1994. Innovation and size of firm. In The Handbook of Industrial Innovation, Dodgson M, Rothwell. R, Edward Elgar.
[48] Hadjimanolis, A. 2000. A Resource-based view of innovativeness in small firms. Technol. Anal. Strateg. Manage. 12 (2), 263-281.

[49] Mintzberg, H. 1978. Patterns in strategy formation. Manag. Sci. 24 (9), 934-948.

[50] Westhead, P. and Storey, D. 1996. Management training and small firm performance: why is the link so weak? Int. Small Bus. J. 14 (4), 13-24.

[51] Mazzarol, T. and Reboud, S. 2005. Customers as predictors of rent returns to innovation in small firms: an exploratory study. Int. J. Entrep. Innov. Manag. 5 (5-6), 483-494.

[52] Jarvis, R., Curran, J., Kitching, J., and Lightfoot, G. 2000. The use of quantitative and qualitative criteria in the measurement of performance in small firms. J. Small Bus. Enterp. Dev. 7 (2), 123-134.

[53] Tidd, J., Bessant, J., and Pavitt, K. 2005. Managing Innovation: Integrating Technological, Market and Organizational Change. John Wiley \& Sons. 